\title{
Trace and Small Phase Analysis : a New Generation of Column for Electron Microprobe
}

\author{
C. Fournier
}

CAMECA, 103 Bd. St-Denis, 92403, Courbevoie cedex, France.

The electron microprobe has become an essential technique for microanalysis in the field of geology, material sciences, microelectronics... Those fields are advancing and require techniques to detect and to measure light and heavy elements in lower concentration, located in particles and smaller phases or thinner layers. In this presentation, we propose to expose the improvements of the electron column of the Cameca SX100 microprobe to fit the specific requirements described above.

We can define several criteria to improve the microprobe column. The smaller phase analysis requires a bright source, an optimized focus of the electron beam, and also a stable low voltage. The thinner layers measurement implies low to high voltages with an optimal control of the voltage. The trace elements quantification needs high beam currents, and low to high voltages, depending on the phase size, or the excited x-ray lines. The light elements analysis requires low voltages and high currents. Hence, the requirements for the new generation of the electron column of the SX100 microprobe must emphasize on a minimal spot size, a high stable current, low to moderate voltages, but not excluding the high voltage to keep the versatility of the machine.

In order to satisfy those criteria, the electron column has been improved with the following characteristics :

- A versatile gun with good vacuum, allowing the use of a $\mathrm{W}$ filament for high voltage (up to $40 \mathrm{kV}$ ) and $\mathrm{a} \mathrm{LaB}_{6}$ or $\mathrm{CeB}_{6}$ cathode for measurement at high spatial resolution. The power supply is designed to heat both cathodes at their optimal working point.

- An optimal alignment and new working mode of the column in order to optimize the beam density for high spatial resolution.

- A new beam current regulation with an extended range: from $0.5 \mathrm{nA}$ up to $1 \mu \mathrm{A}$.

Those improvements compared with the usual column are obvious in terms of spatial resolution (Table 1 and Figure 1). The applications of the optimized electron column are numerous in EPMA for trace analysis or elemental mapping in small areas. We have compared the calculated analytical resolution for different pure standards $(\mathrm{Si}, \mathrm{Fe}, \mathrm{Pb})$ at several beam currents with the $\mathrm{W}$ or $\mathrm{LaB}_{6}$ gun with the new SX100 column. The analytical resolution is defined as the quadratic sum of the probe diameter and the ionization depth calculated with a $\varphi(\rho z)$ model [1]. The results of this comparison (Figure 2) clearly indicate that with the optimized column and LaB6 cathode, it is possible to reach small probe size, compatible with the ionization depth obtained at voltages currently used in EPMA. Thus, an analytical resolution of $1 \mu \mathrm{m}$ can be obtained at $15 \mathrm{kV}$ and 100 or $1000 \mathrm{nA}$ for light and heavy matrix, which makes it possible the trace elements measurement (concentration inferior to $0.01 \%$ weight) in small areas with a reasonable statistical precision. Those results will be discussed in order to evaluate the optimal working domain of the $\mathrm{W}$ gun and the $\mathrm{Lab}_{6}$ gun.

[1] C. Merlet, Mikrochim. Acta 114/115 (1994) 363 
Table 1 : Probe diameter for remarkable current values at $10 \mathrm{kV}$. Comparison between a tungsten (W) and a LaB6 cathode.

\begin{tabular}{|c|c|c|c|}
\cline { 2 - 4 } \multicolumn{1}{c|}{} & \multicolumn{3}{c|}{ Probe diameter $(\mu \mathrm{m})$} \\
\hline Current (nA) & $\begin{array}{c}\text { W and standard } \\
\text { column }\end{array}$ & $\begin{array}{c}\text { W with optimized } \\
\text { column }\end{array}$ & $\begin{array}{c}\mathrm{LaB}_{6} \text { with optimized } \\
\text { column }\end{array}$ \\
\hline 100 & 0,8 & 0,6 & 0,3 \\
\hline 500 & 1,5 & 1,1 & 0,5 \\
\hline 1000 & 2,0 & 1,4 & 0,6 \\
\hline
\end{tabular}

a)

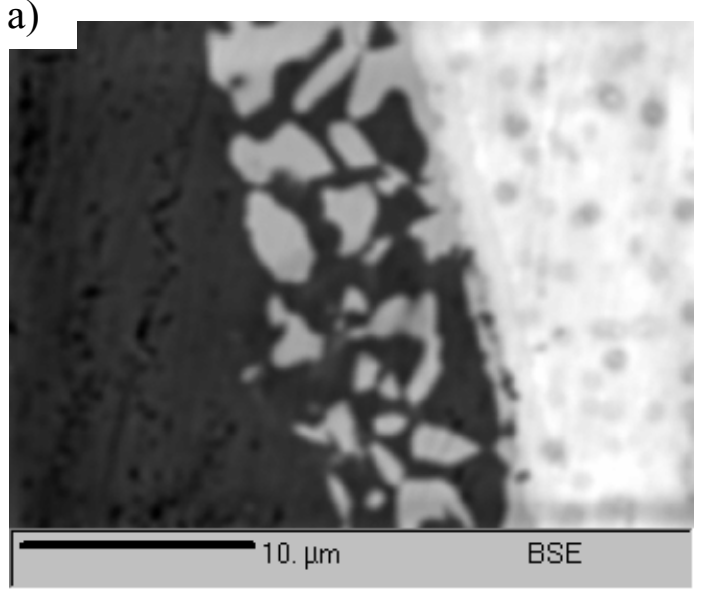

b)

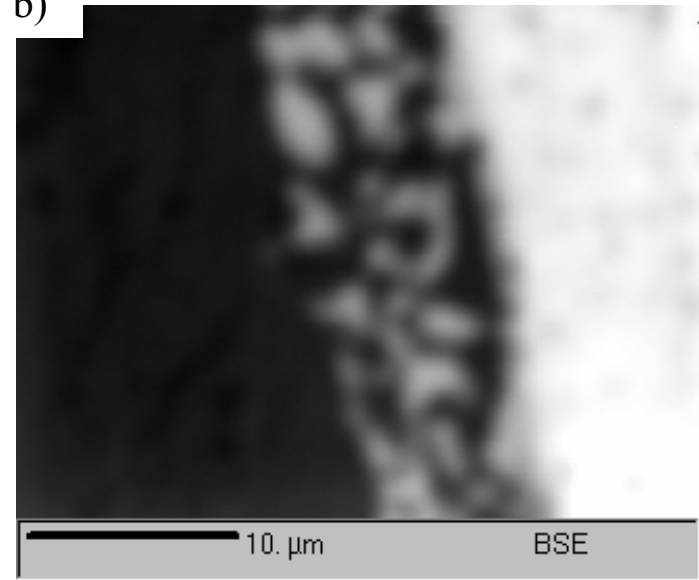

Figure 1 : BSE image on a bronze sample acquired at $10 \mathrm{kV}, 100 \mathrm{nA}$. The image a) is obtained with a $\mathrm{LaB}_{6}$ cathode with the optimized column and the image $\mathrm{b}$ ) is obtained with a $\mathrm{W}$ filament.
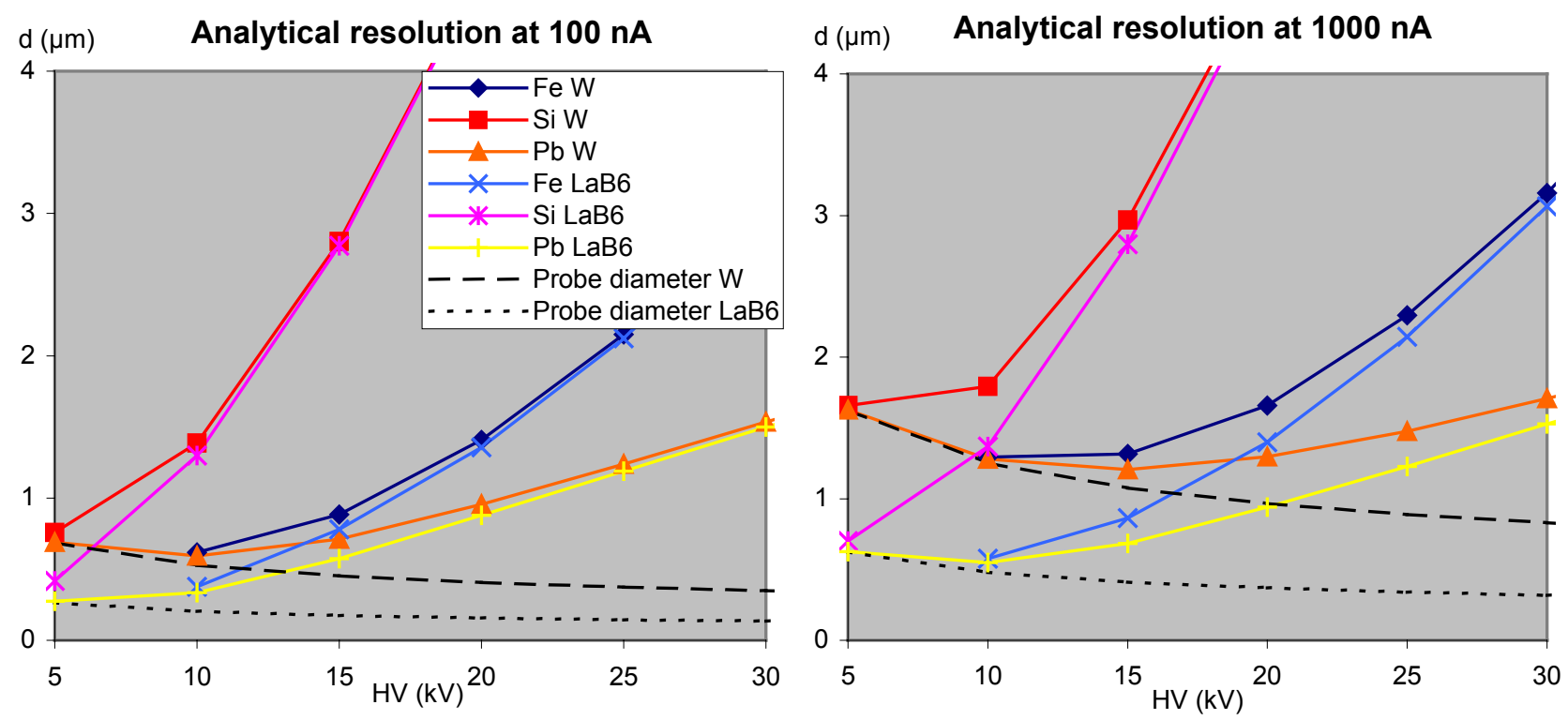

Figure 2: Analytical resolution (d, in $\mu \mathrm{m}$ ) for $\mathrm{Fe} \mathrm{K} \alpha$ in pure $\mathrm{Fe}, \mathrm{Si} \mathrm{K} \alpha$ in pure $\mathrm{Si}$ and $\mathrm{Pb} \mathrm{M} \alpha$ in pure $\mathrm{Pb}$ obtained with $\mathrm{LaB}_{6}$ and $\mathrm{W}$ cathode at $100 \mathrm{nA}$ and at $1000 \mathrm{nA}$. 